\title{
La prensa durante el período rivadaviano: El Argos de Buenos Aires (1821-1825)
}

DOI

http://dx.doi.org/10.1590/2236-463320150910

Rivadavia's the Press During the Period:

El Argos de Buenos Aires (1821-1825)

\section{Mariana Paula Lescano \\ Profesora de Historia en el Instituto de Estudios Iniciales de la Universidad Nacional Arturo Jauretche (Florencio Varela-Buenos Aires / Argentina). e-mail:marianapaulalescano@ gmail.com}

\begin{abstract}
Resumen
El Argos de Buenos Aires fue uno de los periódicos más importantes que se imprimieron en la ciudad de Buenos Aires durante la década de 1820. Su inicio, difusión y final simbolizaron el período de la historia argentina denominado "feliz experiencia", por eso un dato recurrente fue su vinculación con Bernardino Rivadavia. Para ello consideramos que es importante analizar no solamente las líneas públicas sino también tratar de reconstruir el arte de realizar publicaciones periódicas en la década de 1820. Entonces, nos proponemos tratar de comprender porque la historiografía brindo tal jerarquía a este periódico, indagando sobre las condiciones y los condicionamientos de la publicación, así como los vínculos que se establecieron con el gobierno provincial. Asimismo, nos interesaremos en sus editores, y el rol que jugaron en la constitución del nuevo ordenamiento político institucional.
\end{abstract}

\begin{abstract}
The Argos Buenos Aires was one of the most important newspapers that was printed in the city of Buenos Aires during the 1820s. It's beginnings dissemination and final symbolized the period in Argentina's history called "Feliz Experiencia". For this reason, it is no coincidence its connection with Bernardino Rivadavia. Therefore, we believe it is important to analyze not only the public lines, but also try to reconstruct the art of making journals in the 1820s. Then, we intend to try to understand that I offer such a hierarchical historiography this newspaper, inquiring about the conditions and constraints of the publication, and the links that were established with the provincial government. We also will be interested in their editors, and the role they played in the formation of the new institutional political system.
\end{abstract}

Palabras-clave

Prensa, El Argos, escritores públicos, Buenos Aires, espacio público

\section{Keywords}

Newspaper, El Argos, public writers, Buenos Aires, public space 
TERNAVASIO Marcela. Las reformas rivadavianas en Buenos Aires $Y$ el Congreso General Constituyente (1820-1827). En: GOLDMAN, Noemí. Nueva Historia Argentina. Revolución, República y Confederación (1806-1852). Buenos Aires: Sudamericana, 1998.

2

MYERS, Jorge. La Paradojas de la opinión. El discurso político rivadaviano y sus dos polos: el 'gobierno de las luces' y 'la opinión pública, reina del mundo.' En: SABATO, Hilda; LETTIERI, Alberto (comp.). La vida política en la Argentina del siglo $X I X$ : armas, votos y voces. Buenos Aires: Fondo de Cultura Económica, 2003.

3

Ibidem, p.78.

4

Véase ALIATA, Fernando. La ciudad regular: arquitectura, programa e instituciones en el Buenos Aires posrevolucionario, 1820-1835. Bernal: Universidad Nacional de Quilmes, 2006. DAVILO, Beatriz. Los Derechos, las pasiones, la utilidad. El debate intelectual y los lenguajes políticos en Buenos Aires (1810-1827). Caseros: Universidad Nacional Tres de Febrero, 2011. DI STEFANO, Roberto. El pulpito y la plaza. Clero, sociedad y política de la monarquía católica a la republica rosista. Buenos Aires: Siglo XX Editores, 2004. GALLO, Klaus. Un escenario para la 'feliz experiencia'. Teatro, política y vida pública en Buenos Aires, 1820-1827. En: BATTICUORE, Graciela; GALLO, Klaus; MYERS, Jorge (eds). Resonancias románicas. Ensayos sobre la vida cultural Argentina (1820-1890). Buenos Aires: EUDEBA, 2005. GONZALEZ BERNALDO DE QUIRÓS, Pilar. Civilidad y política en los orígenes de la Nación Argentina: la sociabilidad en Buenos Aires, 1829-1862. $2^{\text {a }}$ edición. Buenos Aires: Fondo de Cultura Económica, 2008. MYERS, Jorge. La cultura literaria del período rivadaviano: saber ilustrado y discurso republicano. En: ALIATA Fernando; MUNILLA LACASA Maria Lía (eds.). Carlo Zucchi y el Neoclasicismo en el Río de la Plata. Buenos Aires: Eudeba/Instituto Italiano de Cultura de Buenos Aires, 1998. p.131-148.
Buenos Aires a principios de la década de 1820

En 1820, la provincia de Buenos Aires se organizó autónomamente bajo un régimen republicano. Se crearon nuevas instituciones de gobierno y se modificaron algunas de las existentes en la búsqueda por conseguir cierta estabilidad y legitimidad política luego de la crisis provocada por la caída del gobierno central. Este proceso de innovación institucional significó: la disolución de los cabildos y el establecimiento de la Sala de Representantes - los representantes elegidos a partir de la implementación de un sufragio amplio -, un gobernador a cargo del poder ejecutivo provincial con un mandato de tres años y la instauración de una novedoso sistema judicial basado en la Justicia en Primera Instancia y los Jueces de Paz. Luego de una serie de conflictos, el consenso surgió en torno a la figura de Martín Rodríguez, quien gobernó la provincia hasta 1823 y contó con la asistencia de Bernardino Rivadavia, como Ministro de Gobierno, y Manuel García en Hacienda. No obstante, las reformas políticas no fueron las únicas implementadas: también ejecutaron una serie de reformas económicas, financieras, administrativas, culturales y religiosas. ${ }^{1}$

El grupo dirigente que orientó la administración provincial es conocido historiográficamente con el nombre de "Partido del Orden" - aunque las fuentes no hacen referencia a la existencia de dicho partido -, y su personaje más destacado fue el ministro Bernardino Rivadavia. Este sector dirigente lo conformaron parte de los miembros de la nueva legislatura y los ministros del Gobernador Martín Rodríguez. Entre ellos podemos destacar a los hermanos Rivadavia, Julián Segundo Agüero, Ignacio Núñez, Valentín Gómez, Manuel José Gracia y Vicente López y Planes. Sin embargo, los rivadavianos funcionaron bajo una lógica de círculo o facción, más allá que contaron con un amplio consenso entre la elite porteña; esto les permitió operar una renovación cultural, artística e intelectual en Buenos Aires $^{2}$. Entre los miembros del grupo rivadaviano podemos destacar una característica común a todos ellos: individuos que habian participado de la vida política en período anterior a la revolución. Por eso, algunos autores consideran que su estructura de sentimiento era 'neo-borbónica', expresada en sus concepciones sobre el Estado y cómo este se debía relacionar con la sociedad: "una concepción exaltada de la prerrogativa de los funcionarios del Estado y del deber de obediencia que incumbía a sus gobernados". ${ }^{3}$ La elite gobernante autora de estas reformas ejecutó una serie de novedosas prácticas políticas y civiles que buscaron consolidar el nuevo régimen provincial: la publicación de los debates en Sala de Representares, la diversificación de la prensa política y polémica, y la multiplicación de los ámbitos de sociabilidad, emergiendo una nueva cultura política que complementó las novedades institucionales implementadas a partir de la formación del Estado Provincial. ${ }^{4}$

En este contexto, nuestro propósito será analizar las particularidades de un periódico publicado bajo este clima reformador, El Argos de Buenos Aires: sus características, las condiciones de redacción y publicación, su recepción, sus intereses en la coyuntura política de la década 1820. Entonces, revisaremos los vínculos que se establecieron entre los encargados de llevar adelante el periódico y los sectores dirigentes del gobierno provincial.

\section{El Argos de Buenos Aires en la historiografía}

El Argos de Buenos Aires apareció por primera vez en las calles porteñas el 12 de mayo de 1821 . Fue un periódico de carácter político y noticioso que 
El Argos de Buenos Aires del año 1821. Reimpresión facsimilar. Serie Biblioteca de la Junta de Historia y Numismática Americana. Buenos Aires: Academia Atelier de Artes Gráficas Futuras, 1931. v.X. EL ARGOS DE BUENOS AIRES. Buenos Aires, n.2, 19 de mayo de 1821.

6

URQUIZA ALMADOZ, Oscar. La cultura de Buenos Aires a través de su prensa periódica, 1810-1820. Buenos Aires: EUDEBA, 1972.

7

BELTRÁN, Oscar. Historia del periodismo argentino: pensamiento y obra de los forjadores de la patria. Buenos Aires: Espasa-Calpe Argentina, 1943. GALVÁN MORENO, Celedonio. El periodismo argentino. Buenos Aires: Claridad, 1944. SENADO DE LA NACIÓN. Hemerografia. Biblioteca de Mayo. Buenos Aires, v.10, p. 5240-5720, 1960. Dentro de estas perspectivas tradicionales sobre el estudio de la prensa podemos encortar también trabajos más recientes DE MARCO, Miguel Ángel. Historia del periodismo Argentino: desde los orígenes hasta el centenario de mayo. Buenos Aires: EDUCA, 2006.

GUERRA, François-Xavier; LEMPÉRIÉRE Annick (ed). Los espacios públicos en Ibero América. Ambigüedades y problemas. Siglos XVII-XIX. México: Fondo de Cultura Económica, 1998.

9

ALONSO, Paula. Construcciones impresas.

Panfletos, diarios y revistas en la formación de los estados nacionales en América Latina, 1820-1920. Buenos Aires: Fondo de Cultura Económica. 2003.

10

GOLDMAN, Noemí; PASINO, Alejandra. Opinión pública. En: Noemi, GOLDMAN (ed.) Lenguaje y revolución. Conceptos políticos claves en el Río de la Plata, 1780-1850. Buenos Aires: Prometeo Libros, 2008. p.99-113.

11

GOLDMAN, Noemí. Libertad de imprenta, opinión pública y debate constitucional en el Río de la Plata (1810-1827). Prismas, Revista de Historia Intelectual, Universidad Nacional de Quilmes, n.4, p.9-20, 2000 circuló hasta 1825 con el objeto, según enunció, de "ilustrar al pueblo" de la provincia. El nombre del periódico aludía a un personaje de la mitología griega que tenía la habilidad de verlo todo, porque en algunas versiones tenía cuatro ojos -dos que veían hacia adelante y 2 hacia atrás. Pero según en, tenía cien ojos de los cuales 50 permanecían despiertos mientras los otros 50 dormían, pudiendo, de esa manera, observar todo lo que sucedía. La metáfora del nombre refería, entonces, al rol que debía cumplir el periódico en la sociedad porteña, marcando su carácter noticioso, tal como lo señaló el corresponsal Ilamado el argentino: "Pero lo que importa sobre manera es, ya que V. ha tomado el arduo oficio de Argos, no consienta que lo adormescan, para que logremos que sus cien ojos, y con las mil lenguas que tiene la prensa penetre y sepamos todo cuanto suceda y pase".5

Las diversas referencias historiográficas al Argos destacaron la preeminencia que tuvo el periódico a lo largo de la década de 1820, así como su irremediablemente vinculación con Bernardino Rivadavia. El Argos fue retomado una y otra vez tanto por quienes estudiaron dicho período como por quienes indagaron en la historia del periodismo argentino. Los primeros recorrieron sus páginas en la búsqueda de datos, información y curiosidades que contribuyeran a sus investigaciones, utilizando a los periódicos para cotejar información, aunque fue poco usual que se estudie estos impresos como el objetivo mismo de la investigación. ${ }^{6}$ Mientras que la historia del periodismo vio en el Argos la gran obra periodística de su época. Estos trabajos dedicados al estudio de los prensa del siglo XIX se preocuparon por realizar una antología de los papeles publicados a partir la Revolución de Mayo y nos legaron una exhaustiva descripción de los mismos: tiempo de publicación, cantidad de números editados, imprenta a cargo, editores, y las principales preocupación de sus páginas, etc. ${ }^{7}$ Aunque no podemos negar el caudal informativo al máximo detalle, nos encontramos con un análisis bastante escueto cuando pretenderemos ir más allá de sus descripciones.

En los últimos años, los impresos públicos y los periódicos se convirtieron en objeto de indagación histórica, como consecuencia del crecimiento de los estudios sobre el espacio público. Estos trabajos reconstruyeron sus condiciones de producción y sus espacios de circulación, así como el lugar que ocuparon en los diferentes debates políticos inaugurados por la crisis del imperio colonial español. ${ }^{8}$ La prensa pasó a ser considerada no sólo como un espacio que reproducía las discusiones de la época, sino como un actor que intervenía en ellas, que participaba y hacia politica. ${ }^{9}$

Desde esta perspectiva nos posicionamos, tomando a la prensa como un actor político surgido a partir de la crisis y la disolución del imperio colonial español. Durante la década revolucionaria, los papeles públicos emergieron con la finalidad de difundir y debatir los nuevos principios políticos; además fueron una herramienta innovadora en la construcción y legitimación del nuevo principio soberano, otorgando un nuevo sentido a la "opinión pública", como control y guía del gobierno. ${ }^{10}$ Este rol que ocuparon los papeles públicos estuvo propiciado por la sanción de la libertad de imprenta - decretos del 20 de abril de 1811 y 26 de octubre de 1811 -, que permitía a los hombres publicar libremente sus ideas sin censura previa. Además, los decretos establecieron la creación de una Junta Protectora de la Libertad de Imprenta para contener los abusos que se pudieran cometer, y mantenía la estricta censura para los temas religiosos ${ }^{11}$. 
Marcela Ternavasio muestra como, a partir de la década de 1820 y de la ley electoral, surgieron nuevas formas de visibilizar las prácticas que definian la delegación del poder soberano. En consecuencia, la deliberación libre y abierta en el espacio público, por ejemplo la prensa o los debates en la Sala de representantes, fueron claves a la hora de construir los nuevos consensos. TERNAVASIO, Marcela. La visibilidad del consenso. Representaciones en torno al sufragio en la primera mitad del siglo XIX. En: SABATO, Hilda; LETTIERI, Alberto (comp.). La vida política en la Argentina del siglo XIX. Armas, votos y voces. Buenos Aires: Fondo de Cultura Económica, 2003.

13

GOLDMAN, Noemi. Libertad de imprenta..., Op. Cit.; MYERS, Jorge. La Paradojas de la opinión..., Op. Cit.

14

A principios de marzo de 1821, el padre Castañeda fue sancionado por abusar de la libertad de prensa dado que su actuación ofendió "la decencia pública, violando los más sagrados respetos, burlando a las autoridades, presentando en ridículo la conducta y magistrados del pais, y atropellando de modo nunca visto las personas de carácter y opinión bien establecidas con imputaciones indecentes, groseras y calumniosas hasta el extremo de penetrar en los secretos recónditos de la vida privada de los ciudadanos, que la ley misma respeta". BELTRÁN, Oscar. Op. Cit., p.150.

15

Cuadro que expresan las cantidades de publicaciones periódicas. Resumen numérico de las publicaciones periódicas entre 1821-1825. Extraido de GALVÁN MORENO, Celedonio. 0p. Cit.

\begin{tabular}{|c|c|c|c|c|}
\hline 운 & $\begin{array}{l}\frac{c}{d} \\
\stackrel{n}{x} \\
\stackrel{4}{x}\end{array}$ & 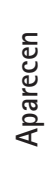 & 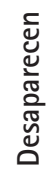 & 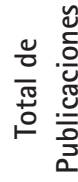 \\
\hline 1821 & 9 & 10 & 9 & 19 \\
\hline 1822 & 9 & 16 & 16 & 25 \\
\hline 1823 & 8 & 12 & 12 & 20 \\
\hline 1824 & 8 & 6 & 6 & 14 \\
\hline 1825 & 8 & 9 & 9 & 17 \\
\hline TOTAL & 42 & 53 & 52 & 95 \\
\hline
\end{tabular}

16

El Argos de Buenos Aires del año 1822.

Reimpresión facsimilar. Serie Biblioteca de la Junta de Historia y Numismática Americana. Buenos Aires: Academia Atelier de Artes Gráficas Futuras, 1937. v.XIV. EL ARGOS DE BUENOS AIRES. Buenos Aires, n.50, 10 de julho de 1822.

17

MYERS, Jorge. Una revolución en las costumbres: nuevas formas de sociabilidad en la elite porteña, 1800-1850. En: DEVOTO, Fernando; MADERO,

Marta (comp.). Historia de la vida privada en

Argentina. País Antigua. Tomo 1: De la Colonia a 1870. Buenos Aires: Taurus, 1999.

18

EL ARGOS DE BUENOS AIRES. Buenos Aires, n.1, 19 de janeiro de 1822.
Durante la década siguiente, la prensa acrecentó su lugar destacado como actor político, al acentuar su carácter de dispositivo pedagógico en la formación de la ciudadanía". La "opinión pública" se transformó en uno de los motores de la vida política, siendo la prensa la que debía garantizar el desarrollo de la ilustración en los pueblos. Pero también generaron en la sociedad y los espacios de poder importantes debates sobre su accionar y los abusos que pudieran cometer ciertos redactores que ponían en peligro a la sociedad. ${ }^{13}$

\section{El Argos de Buenos Aires, 1821-1825}

Diversos trabajos sobre la historia del periodismo concordaron sobre el estallido en la publicación de papeles impresos durante la primera mitad de la década de 1820 relativa libertad que rigió para dicha actividad. Los debates acerca de la libertad de imprenta y los abusos fueron a lo largo de 1820-1821, finalmente se mantuvo en vigencia del decreto de octubre de 1811, sólo se modificó la composición de la Junta Protectora de la Libertad de Imprenta, para asegurar un mayor castigo a los abusos a través de la justicia ordinaria. ${ }^{14}$ De esta manera, la obra reformadora de los rivadavianos fue seguida, apoyada y/o criticada desde la prensa periódica, donde encontramos tanto sus comentaristas como detractores. Entre los principales papeles publicados en el período podemos destacar: La Abeja, El Patriota, El Ambigú, Eco de los Andes, El Nacional, El Argentino, María Retazos, La Revista de Salta y La Verdad Desnuda, entre muchos otros. ${ }^{15}$ La construcción del espacio público y la importancia de la circulación de los periódicos fue una obsesión de la facción gobernante, y el Argos, en consonancia con estas ideas, utilizó su influencia en el mismo sentido.

\footnotetext{
Este ramo va abundando en Buenos Aires, y en término que hacen un grande honor al país sirviéndole también de sumo provecho. Semanalmente se dan tres periódicos distintos. Uno puramente oficial con el título registro: otro mixto que se titula Espíritu, y el presente que es el Argos del cual en lugar de los dos números que se dan en la semana, pronto empezarán á publicarse tres. Hay también tres periódicos mensuales. El uno denominado Registro estadistico á expensas de los fondos públicos, con tres y á veces cuatro pliegos de material. El otro La Abeja Argentina sostenido por la sociedad literaria con cinco pliegos; y el tercero cuyo primer número se ha repartido el 5 del corriente, y tiene de título -el Ambigú de Buenos Aires, por una sociedad de Amigos del Pais. ${ }^{16}$
}

Si prestamos atención, el redactor clasificó los papeles que circulaban en Buenos Aires a mediados de 1822 diferenciándolos según su periodicidad -mensuales y semanales-; y su procedencia - una sociedad civil, del estado, o mixtos-. Sin embargo, el Argos no reconoció filiación alguna con el gobierno, problemática que desarrollaremos más adelante. Desde el periódico se aplaudió con entusiasmo la gran cantidad de publicaciones circulantes por la ciudad, cuando el gobierno porteño estaba implementando las medidas tendientes a crear y consolidar un espacio público, así como para moldear las prácticas de la sociedad. ${ }^{17}$ Más allá de la cantidad de periódicos publicados en la década de 1820, los propios actores reconocieron el faltante de periódicos en la ciudad. Por ejemplo, seis meses antes de la cita anterior, a principios de 1822, el Argos expuso: "La suspensión del Argos, del Boletín de la Industria y del periódico denominado El Patriota, dejó al 
El Argos de Buenos Aires y el Avisador Universal, año 1824. Reimpresión facsimilar. Serie Biblioteca de la Junta de Historia y Numismática Americana. Buenos Aires: Academia Atelier de Artes Gráficas Futuras, 1941. v.XIX. EL ARGOS DE BUENOS AIRES Y EL AVISADOR UNIVERSAL. Buenos Aires, n.61, 11 de agosto de 1824.

20

Esta idea es rebatida por el hijo de Santiago Wilde, para quien su padre fue el único precursor del periódico: "El señor Núñez, campeón de la reforma que entonces se operaba en la sociedad de Buenos Aires, contribuyó, es verdad, con sus escritos a dar importancia a este periódico, pero no fue su fundador". WILDE, José. Buenos Aires desde 70 años atrás (1810-1880). Buenos Aires: EUDEBA, 1960

21

MYERS, Jorge. Introducción: Los intelectuales latinoamericanos desde la colonia hasta los inicios del siglo XX. En: Idem (ed.). La ciudad Letrada, de la conquista al modernismo. Historia de los intelectuales en América Latina. Buenos Aires: Katz, 2008. v.l, p.29-50. pueblo de Buenos Aires en una posición casi absolutamente reservada para con lo interior, y para con lo exterior del territorio" ${ }^{18}$. La misma preocupación apareció en 1824 cuando se publicó el prospecto de un nuevo periódico, El Argentino: "Convencido de la necesidad en que se halla nuestro pueblo de un periódico nuevo para llenar el vacío que dejan los 2 papeles que se redactan [El Argos y el Registro Oficial], se han propuesto los empresarios de él (...) Sin embargo, quieren anticipar por medio de este aviso, ciertas observaciones al caso, que juzgan servirán como garante inequívoco, en el compromiso que aparecerá ya contraído con el público ilustrado"19.

Cuando recorremos las páginas del Argos, nos encontramos con esta preocupación reiterada de sus editores sobre la de papeles públicos. Entonces, no es tan sencillo reducir la cantidad de periódicos publicados como una fiebre editorial, hay que pensarlo a partir del rol que tenían que cumplir dichos periódicos.

Como ya mencionamos, el Argos fue un periódico de carácter político y noticioso. Los iniciadores de este proyecto fueron Ignacio Núñez y Santiago Wilde. ${ }^{20}$ Luego del primer año de publicación, la responsabilidad de editar el Argos pasó a manos de la Sociedad Literaria, en 1822, y los editores rotaron entre los miembros de la asociación, mientras que al año siguiente la redacción del papel estuvo a cargo de uno sólo que recibió una retribución por dicha tarea, el Deán Gregorio Funes. Con la disolución de la Sociedad Literaria, en 1824, Ignacio Núñez fue nuevamente el responsable del papel, quien extendió su nombre: El Argos de Buenos Aires y Avisador Universal - separando la información de los avisos. Finalmente, en su último año de existencia el papel estuvo a cargo de Domingo Olivera. El periódico llegó a su fin el 3 de diciembre de 1825, debido a los conflictos surgidos entre el editor del Argos y el gobernador de Buenos Aires, Gregorio Las Heras.

Esta breve descripción nos permite pensar que es imposible tomar al Argos de Buenos Aires como un todo homogéneo, más allá de su afinidad y cercanía constante al ministro Rivadavia, cada uno de los editores que participaron de su confección lo signaron de sus preocupaciones, problemáticas, así como de sus amigos y enemigos. Además, fue cambiando su perspectiva dependiendo de si se trataba una obra colectiva o una obra individual. La historiografía por lo general reconoció dos períodos 1821 y el resto de la publicación; sin embargo, aquí proponemos la segmentación presentada en la propia colección, las tres veces que reinició la numeración: 1821,1822 y 1824 , y dentro de ellas los cambios de editores que especificamos más arriba. Por otro lado, tendieron a enumerar a quienes fueron los editores de los periódicos, sin prestar atención a sus contactos e influencias ni al rol específico que jugaron en los espacios públicos donde circulaban los papeles que ellos editaban. Específicamente, a lo largo de la década revolucionaria los editores vivieron una inmensa transformación radical en su tarea, porque tuvieron que dejar de ser letrados/funcionario, encargados de llevar las luces al pueblo, para convertirse dirigentes de un estado independiente que tenían que legitimar sus decisiones ante el soberano, el pueblo. ${ }^{21}$

El formato y el contenido del Argos adquirieron cierta regularidad con el paso de los años, si bien no compartió siempre el mismo diagrama. En líneas generales, podemos identificar la publicación de noticias de todo el mundo subdivididas geográficamente: Noticias de Afuera - Europa, Asia, África, Campañas de San Martín y Bolívar, Estados Unidos, y Brasil -, luego 
22

EL ARGOS DE BUENOS AIRES Y EL AVISADOR UNIVERSAL. Buenos Aires, n.8, 11 de febrero de 1824.

23

EL ARGOS DE BUENOS AIRES. Buenos Aires, n.16, 4 de agosto de 1821.
24

El Argos de Buenos Aires año 1823. Reimpresión facsimilar. Serie Biblioteca de la Junta de Historia y Numismática Americana. Buenos Aires: Academia Atelier de Artes Gráficas Futuras, 1939 v.XVIII EL ARGOS DE BUENOS AIRES. Buenos Aires, n.13, 12 de febrero de 1823 aparecieron diferenciada Europa de América; Provincias del Río de la Plata, donde se incluía las novedades provenientes de Paraguay y la Banda Oriental; Buenos Aires, que abarca desde sesiones de la legislatura hasta reseñas de obra de teatro, así como la publicación de avisos privados y la información portuaria. Pero está división no se mantuvo a los largo de los cinco años que duró la publicación: por ejemplo, en 1824 se publicaron noticias en la sección "Europa y América" donde estaban incluidas las noticias sobre de los reconocimientos de las independencias americanas, o los vínculos que se establecian entre las nuevas naciones y sus antiguas metrópolis. Por último, solamente en 1825 existió una sección específica, que inicia el papel, con la opinión de los editores sobre algún tópico de actualidad, que primero a apareció con el nombre de 'El Argos' y luego directamente con el encabezado de 'Los Editores'.

En esta época, había dos tipos de contenido que llenaban las publicaciones; en primer lugar, cuando se publicaban noticias, novedades propiamente dichas, que informaban, por ejemplo, de los últimos acontecimientos de las Guerra de Independencia o las disposiciones de las Cortes europeas. Las noticias por lo general llegaban a través de otros periódicos a los que el Argos accede: "Los editores del Argos rinden las gracias á los señores Tayleur, Cartwright y compañia por haberse servido ofrecer y franquearles las gacetas de Gibraltar desde noviembre 24 hasta 15 de diciembre. Se las devolverán, después de extractar de ellas los artículos que parezcan de mayor interés".22 Asimismo, la publicación de novedades extraídas de cartas privadas, también podemos encontrar la reproducción de documentación oficial y el infaltable rumor que llega a oídos de los editores. Por ejemplo, esto publico el Argos sobre una supuesta ocupación realista en Salta: "Pero algunos avanzan á decir, que alli se ha jurado la constitución española. Se ignora los fundamentos de esta noticia".23 Siguiendo la lectura atenta de la Argos y las características de los circuitos de información, podemos sugerir que conseguir novedades para llenar las páginas de un periódico no fue una empresa fácil de realizar.

Por otro lado, nos encontramos con comentarios y análisis de situaciones conocidas hasta el momento, aunque esto era constante. Solamente en el último año de publicación el periódico iniciaba con una editorial como una sección estable e independiente del resto del contenido publicado. Pero cuando no llegaban novedades y se llenaban los espacios vacíos con poemas e incluso sátiras, la siguiente es sobre la ocupación lusitana en la Banda Oriental:

\footnotetext{
Eran las 9 de la noche y estábamos ya recogidos cuando el ladrido de los perros nos advirtió que se acercaba gente á la casa. Mi hospedante se levantó y se puso á escuchar del lado de adentro de la puerta, cuando el que venía se apeó del caballo y tocó á puerta.

- ¿Quién es? Dijo señor Ramón (que así se llamaba.)

Continental. - Antonio Joaquín Manoel Prieto Pinto Correira Melo de Peixoto, seu criado.

- No abra, señor Ramon, le dixe, que parecen ser muchos y quien sabe que intenciones traen (..... ${ }^{24}$
}

No obstante, en alguna oportunidad el editor decidió publicar solo medio pliego debido a que:

En tanto los vientos contrarios siguen frustrando las esperanzas de ver arribar á nuestro puerto algunos buques de Europa, tampoco han llegado correo alguno del 
EL ARGOS DE BUENOS AIRES Y EL AVISADOR UNIVERSAL. Buenos Aires, n.53, 14 de julio de 1824.

26

Los socios fundadores según el dado: $1^{\circ}$ Antonio Sáenz, $2^{\circ}$ Cosme Argerich, $3^{\circ}$ Esteban de Luca, $4^{\circ}$ Felipe Semillosa, $5^{\circ}$ Ignacio Núñez, $6^{\circ}$ Julián Segundo Agüero, $7^{\circ}$ Juan Antonio Fernández, $8^{\circ}$ José Severo Malabia, $9^{\circ}$ Juan de Bernave y Madero, $10^{\circ}$ Manuel Moreno, $11^{\circ}$ Santiago Wilde, $12^{\circ}$ Vicente López. El 28 de agosto del mismo año ingresa el número $13^{\circ}$ : Gregorio Funes. El 10 de octubre fue aprobada la incorporación de Juan Cruz Varela. El 3 de enero de 1823 se incorpora Valentín Gómez.

27

Entre 1822 y 1823, la asociación publicó un papel mensual con el nombre de la "Abeja de Buenos Aires", de carácter más científico e ilustrado que noticioso.

28

RODRÍGUEZ, Gregorio. Diario de Reuniones de la Sociedad Literaria: contribución histórica y documental. Buenos Aires: Peuser, 1921. v.1, p.289.

29

Ibidem, p.294. interior; y así como ofrecemos á nuestros Subscriptores pliego y medio ó dos pliegos de una vez, ó extraordinarios, cuando algunas noticias y documentos importantes, creemos hacerles favor ó mas bien justicia, publicando solo medio pliego, cuando como en la actualizada, escasee singularmente materia que les interese. ${ }^{25}$

Todo esto nos lleva a preguntarnos por las dificultades que encontraban los escritos de los periódicos para realizar su actividad, porque una de las principales diferencias entre el Argos y los demás papeles contemporáneos fue justamente la publicación de noticias. Si uno revisa rápidamente otros periódicos de la década como el Centinela, el Patriota o Doña María Retazos encuentra que el comentario y el análisis predominaron sobre la comunicación de noticias y novedades. Entonces, hay que prestar mayor atención al manejo de la información, porque las noticias llegaban todas juntas y habia que saber administrarlas hasta el próximo arribo. Pero también hay que tener en cuenta las condiciones materiales, las vinculaciones con la imprenta encargaban de confeccionar el papel y el tiempo humano que se requería para realizar esta tarea.

\section{El Argos de Buenos Aires a través de las actas de reuniones de la Sociedad Literaria}

Analizamos las actas de la Sociedad Literaria - encargada de la publicación del Argos en 1822 y 1823 - con la intención de reconstruir el "detrás de escena" del periódico, y comprender un poco más sobre la dinámica de funcionamiento del periódico. La Sociedad Literaria de Buenos Aires, fundada el $1^{\circ}$ de enero de 1822 , estuvo indudablemente vinculada con el impetu reformador que le adquirió la provincia en década de 1820. Pero que también se alimentó de la experiencia de las asociaciones que la antecedieron durante la década revolucionaria - la Sociedad Patriótica y la Sociedad del Buen Gusto. Estas, teóricamente, eran espacios de reunión de hombres ilustrados con el fin de influenciar con sus progresos al pais y concibieron a la prensa como el medio ideal para difundir este conocimiento. ${ }^{26}$ Con estas premisas, a partir de 1822 la Sociedad Literaria se hizo cargo de la publicación del Argos con el objetivo de ilustrar a la sociedad porteña, cumpliendo de esta manera un rol pedagógico a partir de la comunicación de noticias. ${ }^{27}$ De esta manera en su primera reunión anunciaron:

\footnotetext{
Que esta reunión tenía por objetivo proponer a dichos señores el establecimiento de en sociedad de amigos de la Provincia, que volviese por el crédito de esta, harto comprometido, a causa de no existir y de no publicarse ningún periódico, que diese a las naciones extranjeras, un conocimiento del estado del País y sus adelantamientos, y que fomentase la ilustración, organizase la opinión, satisfaciendo en interés que justamente desplegaban todos los ciudadanos, por que se crease un periódico instructivo y noticioso en Buenos Aires ${ }^{28}$.
}

Entonces, haciendo referencia a la falta de periódicos, el Argos de Buenos Aires comenzaba su segundo año de publicación, dado que los asociados acordaron publicar dos veces por semana un papel ordinario que "conduzca a formar un canal verdadero de comunicación de noticias"29. Por el uso del nombre no hubo problemas, ya que los redactores de la primera etapa no tuvieron inconvenientes en ceder el nombre a la Sociedad Literaria, más allá de que eran miembros de la asociación. En 1822, la redacción del papel estuvo a cargo de tres de sus asociados, que se dividian en: un de parte exterior, el otro parte interior y el restante se encargaría de la coordinación y corrección; 
30

EL ARGOS DE BUENOS AIRES. Buenos Aires, n.1, 19 de enero de 1822.

31

EL ARGOS DE BUENOS AIRES. Buenos Aires. Loc. Cit.

32

RODRIGUUEZ, Gregorio. Op. Cit., p.388.

33

Hacia 1824, existian las siguientes imprentas: Imprenta de los Niños Expósitos (1780), que en ese año pasa a ser la Imprenta del Estado; Manuel José Gandillas y Cía. (1815), que dos años después cambió su nombre a Imprenta Benavente y Cía.; Imprenta de la Independencia (1817); Imprenta Álvarez y Cía. (1819); Imprenta de Phoción (1820); Imprenta del Comercio (1822); Sres. Hallet y Cía. Editores (1823). Véase ARES, Fabio. Expósitos: la tipografía de Buenos Aires, 1780-1824. Buenos Aires: Dirección General de Patrimonio e Instituto Histórico, 2010.

34

RODRÍGUEZ, Gregorio. Op. Cit., p.302. y todo supervisado por una comisión de la sociedad, que parecería ser que nunca funcionó; los encargados de las secciones debian cambiar cada tres meses. Los primeros miembros encargos fueron Manuel Moreno, Esteban De Luca - reemplazando a Semillosa, que pidió no ocupar el cargo - e Ignacio Núñez. Sin embargo, unos cuantos meses después, estos se quejaron de que no habían sido removidos de sus cargos como lo imponía el reglamento, ya que está era una tarea muy difícil de soportar.

No obstante, hacia fin de año los problemas con la redacción del periódico acrecentaron. Vicente López exteriorizó su disconformidad por ser el único miembro de la sociedad que desempeñaba la función de redactor, y no podía continuar más tiempo en ese cargo. Por otro lado, argumentó que si el Argos se había comenzado a publicarse debido a que no circulaban otros periódicos en el momento de su fundación, pero como ahora esa situación había cambiado, opinaba que se suspendiese la publicación del Argos. Esta exposición provocó un gran debate entre los miembros de la asociación, donde surgieron diversas propuestas: que se redujese a un solo número semanal y que todos miembros se comprometan estén comprometidos a participar como lo indicaba el reglamento; que continuase con los dos números semanales, pero que esté a cargo de un redactor permanente quien recibiría una decidieron que al año siguiente el Argos fuera redactado por un editor permanente, quien debía pertenecer a la sociedad, la responsabilidad recayó en Gregorio Funes. Asimismo, obligaron a todos los miembros a auxiliar al editor con noticias o cualquier otro tipo de trabajos. Esto marca nuevamente la dificultad para conseguir y manejar el contenido a publicar, dada la característica del Argos de ser un periódico noticioso.

Por otro lado, debemos tener en cuenta como se mantenía materialmente el periódico. La impresión la realizaron por cuenta y fondos de la Sociedad, estos fondos surgieron de los aportes que los miembros debían realizar - hasta llegar 600 pesos como capital inicial. También se invitó al gobierno a contribuir monetariamente, aunque sabemos que esto no se concretó. Sin embargo, el gobierno de Buenos Aires suscribió al periódico por 50 ejemplares desde 1822 hasta noviembre de 1825 . Además, suponemos que recibió ingresos por los avisos publicados en el papel, con los siguientes valores: "Avisos que no excedan de 8 renglones impresos 4 reales. Por cada dos renglones mas 2 reales. Por cada vez que se repita un mismo aviso la mitad"30 ; como por la venta del mismo "con un pliego cada número; y su precio será de un real según está establecido.". No obstante, nos resulta imposible saber que utilidades recibieron de la comercialización del Argos; sólo sabemos que en marzo de 1823 la venta de los papeles públicos de la asociación era reducida ${ }^{32}$. Las actas de la Sociedad Literaria establecian que una parte de estas utilidades debian repartirse entre sus redactores, y quienes participasen bajo la forma de comunicados; el resto, cuando sean suficientes, iban a ser utilizados para comprar una imprenta en Londres.

El fin último de la Sociedad eran hacerse de su propia imprenta, este objetivo puede ligarse tanto al ideal ilustrado como a las dificultades prácticas vinculadas con las imprentas porteñas ${ }^{33}$, "debe procurar recursos para habilitarse de una Imprenta propia por medio de las cual pudiese hacer dar los periódicos en la mitad del valor que el uso fijado del pais.". Más allá de reducir el precio de venta, solía ocurrir que las imprentas tenían otras urgencias y dejaba de imprimir los periódicos. En principio, los miembros de la sociedad habian acordado editar sus papeles en la Imprenta de la Independencia, pero resultó que esta era muy cara, 25 pesos cada pliego sin 
Myers afirma, lisa y llanamente: "La Sociedad Literaria era un creación para estatal, no una asociación civil nacida en forma autónoma del seno de la sociedad". MYERS, Jorge. Identidades porteñas el discurso ilustrado en torno a la nación y el rol de la prensa: El Argos de Buenos Aires, 1821-1825. En: ALONSO, Paula. Op. Cit., p.47.

37

En El Argos n.205, del 11 de noviembre de 1825, el editor informó el fin de la suscripción estatal al periódico y los motivos dados por el mismo.

38

RODRÍGUEZ, Gregorio. Op. Cit., p.335.

Ibidem, p.355.

RODRÍGUEZ, Gregorio. Loc. Cit.

papel; en cambio en la Imprenta Expósito: "ofrecían dar cada pliego por 18 pesos sin papel, de una letra mediana, con márgenes estrechos y facultad de insertar letra más pequeña" ${ }^{35}$. Sobre el papel, solo sabemos que consiguieron 100 resmas de buena calidad a 26 reales cada una.

En una primera instancia, la Sociedad habia acordado tirar 500 ejemplares, pero Ignacio Núñez, como tesorero administrador, consideró que estos no alcanzaban para el "servicio público", por lo que mando a tirar 100 más. Los ejemplares se distribuian de la siguiente manera: 100 para la sociedad, 50 para cada uno de los tres lugares de venta de la ciudad, 50 para el gobierno, 300 para la plaza para formar las colecciones que se archivaban e intercambiaban corresponsales de Europa y América. Mientras tanto, Miguel Ochagavia fue el dependiente de la Sociedad, encargado del reparto y de la venta del Argos; así como de la admisión de nuevos suscriptores, con un sueldo mensual de 10 pesos.

Evaluemos ahora la relación entre la Sociedad Literaria y el gobierno de Martín Rodríguez. Las personalidades que participaron y los objetivos de la asociación nos permiten argumentar que la Sociedad Literaria formó parte del programa de reformas impulsado por el gobierno con el fin de crear un espacio público. ${ }^{36} \mathrm{El}$ artículo 44 del reglamento de la Sociedad invitaba al gobierno de la provincia a auxiliarla pecuniariamente; Julián Segundo Agüero, en su carácter de presidente de la asociación, fue el encargado de hablar con Rivadavia para conseguir dichos fondos. No obstante, la retribución monetaria no fue convenida, si consiguieron la suscripción del gobierno por cincuenta ejemplares de cada número. ${ }^{37}$

A fines de Marzo de 1822, la Sociedad recibió un comunicado del Ministerio de Gobierno donde establecía que una serie de premios anuales, cuya ejecución estarian a su cargo. La asociación aceptó la distinción, y rápidamente se puso a trabajar para llevar a cabo el encargo. De esta manera, el número 22 del 2 de abril de 1822, publicó sus comunicaciones con el gobierno y estableció el tópico del premio: "¿Cuáles son las causas que detiene los progresos de la Agricultura en esta provincia, y cuáles los medios de removerlas?". 38

No obstante, hacia mediados de julio, la Sociedad recibo otra propuesta del ministerio, pero esta vez decidió no aceptarla: "que se aumente un número más del 'Argos', en cada semana con el objeto de que se tratara seriamente sobre la cuestión de la ocupación violenta de la Banda Oriental por la nación vecina".39 Este pedido llevó a que la Sociedad replanteara su relación con el gobierno, ya que según sus perspectivas terminarian siendo perjudicial a los propios intereses de la asociación. Finalmente, se acordó la contestación al ministerio informando que la Sociedad no podia hacerse cargo de sacar tres números semanales. En cambio, invitó al gobierno a facilitarle documentos para sus dos publicaciones semanales, pedido que nos vuelve a recordar la dificultad de llenar las hojas con noticias, justamente este fue el argumento de la negativa al gobierno.

Por último, cuando se trató el reglamento para la publicación del Argos en 1823, volvió a surgir la necesidad de definir las relaciones con el gobierno, el socio secretario, Ignacio Núñez expuso:

en la parte interior se ocupase sólo en censurar los actos que lo mereciesen de la administración pública en todos su ramos, sin que jamás el editor ocupase su pluma una sola vez en elogiar dichos actos (...) sin tocar a las personas, y sin necesidad tampoco de hacerlo en una forma anárquica y tumultuosa. ${ }^{40}$ 
41

Ibidem, p.378.
42

LA ABEJA DE BUENOS AIRES. Buenos Aires, n.1, 15 de abril de 1822. Reproducción facsimilar Senado de la Nación. Buenos Aires, Tomo V, p.5247.
Finalmente, las instrucciones que debía observar el redactor permanente del Argos en 1823 estableció:

$1^{\circ}$ Que abra opiniones sobre los negocios públicos de mayor importancia que refieran, censurándolos o aplaudiéndolos según su juicio.

$2^{\circ}$ Que en la censura tenga parte estos dos principios: $1^{\circ}$ no separarse de la decencia y la circunspección; $2^{\circ}$ ilustrar con ellas a las autoridades y enseñar el modo práctico de hacerlos sin tocar en los términos anárquico. (...)

$4^{\circ}$ Que como la censura, a pesar de hacerse con arreglo a estas bases, pueda dar lugar a acusaciones ante la ley, el editor jamás la haga sin estar perfectamente cerciorado de los hechos ${ }^{41}$.

Entonces, las relaciones entre los miembros de la Sociedad Literaria y gobierno porteños fueron estrechas y directas. Por ejemplo, Ignacio Núñez fue oficial mayor del Ministerio de Gobierno - a cargo de Rivadavia; Santiago Wilde fue Contador de Cálculo de la Contaduria General de Gobierno; mientras que Julián Segundo Agüero fue el presidente de la Sala de Representantes. Sin embargo, vemos como la Sociedad Literaria intentó distinguirse y mostrarse independiente del gobierno. En consecuencia, podemos argumentar que los miembros de la Sociedad Literaria, con su legado borbónico, ejecutaron un intento de sociabilidad e imprenta con intenciones ilustradas en un espacio político cultural transformado por el paso de la revolución.

Convencidos por una experiencia tan cierta como funesta, que la mayor parte de los males que hemos sufrido en el curso de la revolución no ha tenido otro principio que la falta de ilustración pública, consiguiente al estado de abyección en que nos tenia nuestra ominosa dependencia de España, hemos creído que el mayor servicio que podiamos prestar á nuestro país, era contribuir para generalizar en toda clase de conocimientos. ${ }^{42}$

Estos hombres ocuparon al mismo tiempo cargos en la administración estatal y en espacios propios de la sociedad civil con la intención declarada de difundir las luces, como si fueran letrados coloniales. Sin embargo, no lograron distinguir la especificidad de la forma de pensar, de actuar e interpretar las relaciones de poder del período posrevolucionario. Ya no existía la posibilidad de desarrollar una cultura letrada e ilustrada plasmada en un sistema de instituciones, como en la época colonial, con el monopolio de las actividades de imprenta. La revolución y la libertad de imprenta cambiaron el lugar y las funciones de los escritores públicos. Ahora estaban al servicio del orden establecido, al que publicitaban y al daban a conocer sus acciones del gobierno - en este caso, las reformas ante el nuevo soberano, el pueblo.

Los rivadavianos, como consecuencia de su legado borbónico, no lograron visualizar esta nueva especificidad de su actividad como escritores públicos. La revolución convirtió a los letrados en publicistas, doctrinarios o críticos. Estos últimos hicieron su aparición en el escenario porteño a fines de 1822, con los debates sobre la reforma religiosa. Las manifestaciones de esta críticas, incluso al interior de la asociación, llevó a que las disidencias no pudieran coexistir dentro Sociedad Literaria. Como consecuencia, esta no pudo sobrevivió mucho tiempo más y, a principios de 1824 , se disolvió. Los otrora miembros de la Sociedad se encontraron desde entonces en veredas opuestas de la arena política, afectando enormemente al Argos. Justamente, a partir de 1824, no sólo pasó a ser un fuerte crítico de la ges- 
43

EL ARGOS DE BUENOS AIRES. Buenos Aires, n. 2 19 de mayo de 1821.

44

Doña Maria Retazos. n.3, 26 de mayo de 1821. En: CASTAÑEDA, Francisco de Paula. Doña María Retazos. Buenos Aires: Taurus, 2001. p.55.

45

EL ARGOS DE BUENOS AIRES Y EL AVISADOR UNIVERSAL. Buenos Aires, n.176, 13 de Agosto de 1825.

46

EL ARGOS DE BUENOS AIRES. Buenos Aires, $n$. 11, 23 de febrero de 1822

47

DIARIO DO GOVERNO. Rio do Janeiro, n.59, 13 de marzo de 1823. v.1, p.246. En línea: <http:// hemerotecadigital.bn.br/acervo-digital/diario-riojaneiro/094170>. Acessado en: 5 abr. 2015. tión del nuevo gobernador Gregorio Las Heras, sino que también abandonó su carácter colectivo para ser editado de forma individual y exclusiva por Ignacio Núñez.

\section{La recepción del Argos}

Pasemos a la recepción del Argos de Buenos Aires en la sociedad porteña y los derroteros por los que circuló. En su segundo número, el Argos agradeció al editor del legendario periódico revolucionario por mencionar su aparición: "Estamos reconocidos al editor de la gaceta ministerial por el favor que nos dispensa, llamando interesante el primer número de nuestro periódico".43 Mientras que el tercer número de Doña María Retazos, editado bajo la pluma incansable del Padre Castañeda, expuso sobre el Argos: "Mi periódico es independiente, y no tiene conexión alguna con esos editores que están alvorotanto al mundo. (...) Sin embargo, yo soy de parecer que un hombre con cien ojos, ó es un hombre con cien puñaladas, ó es un topo, y en cualquiera de los casos no necesita anteojos." ${ }^{44}$

Podemos suponer que los números del Argos circuló en el espacio rioplatense e incluso más allá; la Sociedad Literaria tuvo la intensión de formar colecciones para intercambiarlas con otros periódicos extranjeros. De la información referida en sus páginas, sabemos que establecieron contactos e intercambios con otros periódicos, por ejemplo: la Revista Mensual de Salta, la Gaceta de Montevideo, el Correo del Arauco, la Década Araucana y el Correo de Liverpool: "Agradecemos la invitación y los primeros números que por el conducto de la casa de los señores Taileur, Cartwirigt y compañía, nos han hecho el honor de dirigir los señores editores del interesante Correo de Liverpool para cambiar sus producciones con el Argos".45

No obstante, no siempre los periódicos establecieron intercambios amables entre ellos, algunas veces surgieron fuertes disputas sobre las noticias que publicaban o lo que comentaban sobre ellas. También se repitió esta situación cuando otros periódicos reproducian alguna parte de sus escritos:

En la gaceta de dos lenguas, llamada el Pacífico Oriental, se encuentra seis artículos distintos sobre el Argos, en el corto espacio de dos números, el 9 y el 16 del corriente. ${ }^{46}$

Incluso, encontramos reproducciones del Argos en otros periódicos, por el ejemplo el Diario de Govierno de Río de Janeiro de 1823 sobre la cuestión Orienta comenta:

Lendo o $\mathrm{N}^{\circ} 7$ do Argos de Buenos Ayres de 22 de Janeiro de anno corrente enchi-me de espanto á vista do artigo Buenos Ayres, que passo a extractar (...) nós o ofrecemos aos nossos leitore no próprio idioma originai, seguros de que não folgaram menos de verem assim desmascaradas as intrigas com, que o Argos forceja, mas debalde, por semear o descontentamento, e enredar os negocios daquela importante parte do Império. ${ }^{47}$

El Argos buscó colocar a la provincia, en el momento que se reformaba y modernizaba, a la altura de las ideas del siglo dentro del universo político y cultural del espacio Atlántico. Este era un espacio que entrelazaba, de una costa a la otro, contactos políticos, culturales, personales y comerciales. Los intercambios a través de esta red atlántica permitió la circulación no sólo de libros, periódicos o folletos -que representaban los valores culturales de la época - sino también a los hombres de estado -en 
BAILYN, Bernard. Atlantic History: Concept and contours. Cambridge, Massachussetts: Harvard University Prees, 2005; DÁVILO,

Beatriz. Los derechos, las pasiones, la utilidad: Debate intelectual y los lenguajes políticos en Buenos Aires (1810-1827) Caseros: Universidad Nacional Tres de Febrero, 2011; MORELLI, Federica. La historia atlántica y las revoluciones hispanoamericanas: otras perspectivas de análisis. Boletin del Instituto de Historia Argentina y Americana "Dr. Emilio Ravignani." Buenos Aires, tercera serie, n.33, p.29-33, 2010; PASINO, Alejandra. El español de José María Blanco White en la prensa porteña durante los primeros años revolucionarios. En: HERRERO, Fabián. Revolución: política e ideas en el Río de la Plata durante la década de 1810. Buenos. Aires: Ediciones Cooprativas, 2004; PASINO, Alejandra. Independencia y República: la polémica José Maria Blanco White. Servando Teresa de Mier y su recepción en el Río de la Plata revolucionario. En: ORTEGA, Francisco; CHICANGANA BAYONA, Yobenj Aucardo (eds.). 200 años de independencias: las culturas politicas y sus legados. Medellin: Universidad Nacional de Colombia, 2011. p.73-94. PIMENTA, João Paulo Garrido. Estado y nación hacia el final de los imperios ibéricos: Río de la Plata y Brasil, 18081828. Buenos Aires: Sudamericana, 2011.

49

PICCIRILLI, Ricardo. Rivadavia y su tiempo. Buenos Aires: Peuser, 1960. p.456.

50

EL ARGOS DE BUENOS AIRES. Buenos Aires, n. 3, 26 de mayo de 1821. esta época llegaron los primeros cónsules extranjeros a toda Sudamérica- y de negocios con sus interés específicos. La prensa ocupó un lugar privilegiado en esta conexión al brindar los modelos a seguir y permitir el tránsito de información a través del océano. ${ }^{48}$ Por ejemplo, el filósofo francés Destry Tracy le escribió a Rivadavia en 20 de septiembre de 1823:

Acabo de leer con una alegría inexplicable el artículo inserto ayer en el Journal des Debats, que, sin embargo, no es, en general muy amigo de las ideas liberales y de la libertad. Da un resumen muy sumario, según mi parecer, pero satisfactorio de lo que ha recogido en algunos números de vuestro Argus (sic) y de vuestro Registro Oficial ó Boletín de las leyes ${ }^{49}$.

Entonces, a través de la mirada Atlántica, los editores del Argos forjaron las representaciones del orden político instaurado y de su intención de la insertar al Río de la Plata en el escenario mundial, propósito reflejado en la publicación sistemática de noticias europeas que se condescendian con la actualidad porteña. Entonces, en la diagramación misma del impreso en las primeras páginas de Argos aparecian las noticias internacionales - como en la desproporción de las noticias "de afuera" sobre las locales, vemos cumplirse el objetivo de los editores del colocar a la provincia y la gestión rivadaviana en armonía con las ideas del siglo, representado en su plan de de reformas. Sin embargo, a partir de 1824 esta preponderancia de noticias europeas fue matizada cuando las noticias del "interior" comenzaron a ganar espacio en el impreso, especialmente con la publicación de novedades vinculadas con la elección y el arribo a Buenos Aires de los diputados provinciales que conformaron el Congreso Constituyente, que inició sus sesiones a fines de dicho año.

Pensemos ahora a la repercusión que tuvo el Argos en la sociedad porteña. Los café eran los lugares donde los hombres de la élite porteña se reunian para sociabilizar: leer y comentar periódicos, jugar a las cartas y conversar. En estos espacios, el Argos fue leído, escuchado y comentado. En el tercer número de 1821, apareció un artículo donde el editor respondió a las críticas que oyó de un grupo de caballeros:

\footnotetext{
Notó también que un anciano acababa de leerlo en alta voz, porque mientras le quitaba el paño á sus anteojos les decia:- no me parece mal señores: pero la letra es demasiado menuda: pensaba suscribirme más el tal Argos se imagina que todos tenemos los mismos ojos que él: asi esperaré á que enmiende este defecto.

La letra de los demás periódicos, dijo otro, es sin disputa mucho más cómoda, pero es preciso no olvidar, que por esta razón carecen de materia. ${ }^{50}$
}

En principio no podemos creer en el relato, pero lo podemos interpretar como una manera que tenían los editores de posicionar su periódico frente a sus posibles lectores porteños y el resto escritos que circulaban por la ciudad. Entonces, podríamos decir que el Argos circulaba, era leido y comentado en los espacios de sociabilidad de la elite porteña. En varias ocasiones, los editores publicaron la lista de los subscriptores, donde aparecian los personajes e instituciones más destacadas del ambiente porteño. Sin embargo, no podemos asegurar mucho más respecto a la magnitud de la recepción del Argos por otros espacios.

Por otra parte, el redactor argumentó que no pudo responder in situ los comentarios que escuchó en el café para no revelar su identidad; esta fue otra de las particularidades comunes de los periódicos de la época: el 
51

Ibidem, n.13, 24 de julio de 1821

52

Ibidem, n.5, 9 de junio de 1821.

53

RODRÍGUEZ, Gregorio, Op. Cit., p.357.

54

EL ARGOS DE BUENOS AIRES. Buenos Aires, n.13, 24 de julio de 1821. supuesto anonimato de los editores. Digo supuesto, porque no resultaba muy difícil establecer, tanto para los contemporáneos como para nosotros, quiénes fueron los responsables de los impresos. Algunas veces los mismos editores del periódico se hacian pasar por lectores; por ejemplo, cuando Santiago Wilde simuló ser un corresponsal que proponía una reforma urbana: ponerle nombres a las calles. En este momento se dio el lujo de jugar con lo visible e invisible, con lo público y el anonimato:

\footnotetext{
¡V descubre, señor Argos, grande interés por que no haya una sola cosa que no se nombre, pero entretanto no hay uno a quien $v$ no oculte el suyo!- Pero ya que V. lo desea, comunicaré con gusto á su invisibilidad mi idea sobre el mejor modo de nombrar y numerar las calles y la casa de esta capital (...) Su invisibilidad me dispensara la franqueza, y seguirá creándome su atento amigo.- S. Wilde. ${ }^{51}$
}

Diferentes hipótesis podemos ensayar respecto al anonimato: puede ser simplemente una expresión de desahogo político; tal vez una cuestión de credibilidad de la publicación - no condicionar la lectura por saber quién la escribió -, o para evitar hacer públicos los conflictos entre distintas personalidades y/o facciones. De la lectura del Argos, rápidamente se desprende esta última posibilidad, escapar a la lógica facciosa: "las cuestiones entre los escritores públicos, son entre nosotros más sangrientas que las del campo de batalla: se hacen personales, y el Argos, huira de ellas, tanto por esta razón, como porque su atención distraería, y al tiempo porque es necesario complacer á los lectores".52

Asimismo, en el Reglamento que la Sociedad Literaria le dio al redactor de 1823 tenía un artículo especifico sobre ello: "6 ${ }^{\circ}$ - Queda absolutamente prohibido el comunicar a persona alguna fuera de la Sociedad, el nombre de ninguno de los redactores".53

Sin embargo, los lectores del periódico buscaron identificar a sus redactores, por ejemplo a través de las ideas que ellos exponían, como este corresponsal que intentaba dar con el editor del periódico: "Vién (sic) á mi me parece columbrar que este mi paisano Argos, hace poco ha venido del otro lado del mar océano: la distancia tal vez no le hayan permitido con toda su vista de lince ver nuestras cosas, sino según se le transmitan en el papel, y todos saben que el papel lo admite todo".54

Este predominio de la lógica de anonimato, nos lleva a preguntarnos nuevamente acerca de quiénes eran estos escritores públicos y cuáles eran las funciones que cumplieron en la sociedad. En una primera aproximación a partir de la lectura del Argos de Buenos Aires, postulamos que sus editores, durante los primeros años de la publicación, actuaron siguiendo la lógica de los letrados coloniales: encarnaron un proyecto de prensa ilustrada como filósofos que difundían las luces entre los miembros de la sociedad, sin cristalizar que eran hombres al servicio de una política. Esta no cristalización podemos atribuirla a varios motivos: la estructura de sentimientos neo borbónica de los rivadavianos, el consenso político y cultural en sus primeros años de gestión (1821-1823) y el acción del gobierno en el afán por consolidar un espacio público. Pero hacia fines de 1823 la competencia inter-notabiliar por los cargos electivos tomó tal magnitud que el consenso se quebró, dando lugar a la aparición de nuevos contendientes en la arena política: el llamado partido popular, quien contó, además, con sus propios periódicos: El republicano o El teatro de la Opinión. En esta circunstancia, fue cada vez más evidente que el espíritu detrás del Argos de Buenos Aires no se correspondía con el discurso ilustrado sino que estaban al servicio 
El Argos informó sobre los pormenores de su viaje a Inglaterra, al punto de llegar al grotesco. Por ejemplo, con la reproducción del periódico inglés The Sun del 7 de septiembre de 1824 :"En este buque ha venido el Sr. de Rivadavia, por cuya sabia administración aquel estado ha podido hacer en cuatro años un progreso tan rápido hacia la prosperidad". EL ARGOS DE BUENOS AIRES Y EL AVISADOR UNIVERSAL. Buenos Aires, n.102, 15 de diciembre de 1824 .

56

Ibidem, n.34, 12 de mayo de 1824.
57

El Congreso Constituyente convocado en 1824 tenía como objetivo la organización nacional, por ello fueron convocadas todos los territorios que habian formado parte del virreinato del Río de la Plata. Pero las causas inmediatas fueron la guerra con Brasil y la firma de un acuerdo comercial y político con Gran Bretaña. de una facción política particular. Hacia 1824 el Argos se convirtió en una empresa individual. Los redactores del periódico - Ignacio Núñez y Domingo Olivera, ambos empleados del Ministerio de gobierno durante la década de 1820 - cumplieron un nuevo rol convertidos ahora en publicista de una opción política, su función fue brindar al público lector una explicación clara y válida de las acciones de sus conspicuos.

\section{El Final del Argos de Buenos Aires}

Del primer número que publicó el Argos de Buenos Aires, en 1821, a los últimos de 1825, hay una gran diferencia en cuanto a su contenido, forma, intereses y preocupaciones fueron transformándose con el correr de los años, tornándose un periódico mucho más noticioso que ilustrado, propagandístico de una facción de la elite porteña en particular. Como dijimos, todos los que participaron en algún momento de la redacción del periódico ocuparon cargos en las instituciones provinciales, por lo que era muy difícil separar estas dos actividades. Para ellos, la prensa fue un espacio donde divulgar sus intenciones institucionales, ya sean provinciales o nacionales.

Hacia finales de 1823, la facción rivadaviana que gobernaba la provincia de Buenos Aires desde 1820 perdió el consenso del que había disfrutado a principios de la década. Se escucharon las primeras voces de crítica hacia las medidas gubernamentales y en marzo de este año un levantamiento encabezado por Gregorio Tagle puso en jaque los cimentos de las instituciones instauradas en la provincia. Asimismo, aparecieron sectores de la elite que le disputaron su lugar en los cargos de gobierno, el llamado partido popular encabezado por Manuel Dorrego a la cabeza. Al acercarse el recambio de las autoridades provinciales, el predominio de la facción rivadaviana se diluyó en presencia de estos nuevos sectores de la elite que le disputaron, y en el corto plazo le ganaron, su lugar como los representantes del pueblo de Buenos Aires. Por primera vez, desde la creación de la Sala de Representantes, el grupo rivadaviano perdió el control de la institución porteña y el General Juan Gregorio Las Heras fue elegido como el nuevo gobernador provincial. Mientras tanto, Rivadavia pasó a un ostracismo voluntario en Gran Bretaña. ${ }^{55}$ Por su parte, el Argos celebró con toda pompa el funcionamiento armónico de la ingeniería institucional:

El recibimiento del nuevo Gobierno en este dia hecho en el órden establecido por la ley, es el primer acto de su género que se presencia en esta capital después de la revolucion, y la primera prueba práctica que este es tambien el medio para lograr que la separacion de un Gobierno se haga sin causar ni el descredito del país, ni la ruina de su fortuna, ni las desgracias ó las alarmas de las familias. ${ }^{56}$

No obstante, en paralelo se convocó a las Provincias para participar del nuevo Congreso Constituyente, bajo estas circunstancias, el editor del Argos le prestó mucho más atención a las cuestiones provinciales. Como enunciamos más arriba, no se puede entender al Argos de Buenos Aires como un periódico con características inmutable a lo largo de sus casi 5 años de publicación. Hacia 1824, podemos decir que de a poco fue perdiendo su "ministerialismo". El cambio de orientación, podemos vincularlo con la modificación del proyecto de la facción rivadaviana: perdida la provincia fueron por la organización nacional en el Congreso Constituyente ${ }^{57}$, y el Argos evidenció esta innovación de objetivos.

En consecuencia, desde 1824 en las páginas del periódico aparecieron los primeros cuestionamientos al gobierno de Buenos Aires, tanto a 
EL ARGOS DE BUENOS AIRES Y EL AVISADOR UNIVERSAL. Buenos Aires, n.69, 4 de septiembre de 1824

59

Se publico entre 17 de diciembre de 1824 y el 10 de diciembre de 1825, impreso en la imprenta de Hallet en Buenos Aires. Entre sus editores se encuentra Baldomero Garcia, José Francisco Ugarteche, Manuel Sanz de Cavia y Manuel Dorrego. OSCAR, Beltrán. Op. Cit., p.159.

60

Se publicó entre 24 de diciembre de 1824 y el 30 de marzo de 1826, como redactores de este periódico fueron identificados Valentín Alsina e Ignacio Núñez. Se imprimió en el Taller Independencia.

61

EL ARGOS DE BUENOS AIRES. Buenos Aires, n.202, 5 de noviembre de 1825 .

62

EL ARGOS DE BUENOS AIRES. Loc. Cit. la Sala de Representantes como al nuevo gobernador. El Argos cuestiono la labor legislativa de la cuarta legislatura - formada por los que antes habían sido los opositores: "sin que ahora nos entretengamos á demostrar, que ni aun en los puntos que abrazan las mociones ni en ningunos otros de los demás ramos que comprenden el servicio público, la cuarta legislatura ha producido cosa alguna sustancial".58

A lo largo de 1825 hubo un cambio en la coyuntura porteña dada por la doble institucionalidad: el Congreso General Constituyente y el gobierno de la provincia de Buenos Aires, este a su vez se encargaba de ejecutar las leyes elaboradas por el primero. En el primero predominaba la facción rivadaviana, mientras que en la Sala porteña los conspicuos del partido popular.

Cerca del inicio de las sesiones del Congreso, en diciembre de 1824, dos nuevos periódicos aparecieron en Buenos Aires: El Argentino ${ }^{59}$ y El Naciona ${ }^{100}$. El primero expresaba en sus páginas las ideas del llamado partido popular, encabezado por Manuel Dorrego. Por su parte, El Nacional presentaba las ideas políticas de la facción rivadaviana - al igual que el Argos. Cuando analizamos los prospectos de ambos periódicos, vemos que entre ellos compartieron las mismas motivaciones y los mismos objetivos: enfrentar la apatía del pueblo frente a los asuntos de interés públicos y uniformar la opinión. Hay una pequeña diferencia en cuanto a la publicación de sus prospectos: mientras El Nacional hizo en su primer número y los editores firmaron con el nombre del periódico, El Argentino lo publicó en el Argos cuatro meses antes de iniciar sus actividades públicas - suponemos que para buscar posibles suscriptores -, bajo la firma de 'los empresarios'. El cambio no pasó por considerar al papel público como un negocio - nadie podía solventarse económicamente mediante esta actividad -, sino por el rol que cumplieron los periódicos, vinculados a la necesidad de publicitar una opinión en particular en un contexto donde los disputas políticos fueron en constante crecimiento.

A este clima hay que sumarle el conflicto latente con el Imperio de Brasil por los territorios ubicados al este del Río de la Plata. En esta puja, el editor del Argos, fue un convencido publicista del gobierno nacional. Para el editor era cada vez más importante la labor del poder público y "la necesidad ya urgente de organizar ya un estado".61 Ello se vinculó con las críticas sobre las actuaciones de los ministros porteños en tanto encargados del poder ejecutivo nacional. ¿Qué fue lo le reprochó el editor del Argos en sus páginas? Dos cuestiones principales: estar a cargo del poder ejecutivo nacional pero no ejecutar las leyes sancionadas por el Congreso - en particular la de reforzar la línea del Uruguay y la de formación de un Ejército Nacional - y haber intentado renunciar, en varias ocasiones, a dicho poder. El Argos acusó directamente al gobierno de Buenos Aires de dar un paso en falso: "un paso que hacia retroceder á Buenos Ayres hasta las épocas en que se ha dicho que no prevalecía en los ministerios la razon pública sino tambien acomodamiento personal engendrado y nutrido por la desmoralización".62 El editor del Argos pidió expresamente a la legislatura porteña que obligara al gobernador y sus ministros - Manuel García y Francisco Fernández de la Cruz - a ejecutar las leyes sancionadas por el Congreso. Entonces, para el Argos el problema radicaba en que el "cuerpo nacional" no tenía quien ejecute sus leyes y los hombres públicos, los administradores de la provincia, actuaban en función de sus propios intereses.

Entonces, el Argos se alineó con la posición del Congreso Constituyente, subiendo, de esta manera, el tono de las críticas a las autoridades 
de porteñas. A lo que el gobierno provincial respondió no renovándole la suscripción por 50 ejemplares que mantenía desde 1822, quedando reducida a solamente por 3 ejemplares, a ello el editor respondió: "que si á algunos pocos no puede agradar; complacerá indudablemente á muchos que quisieran ver desterrado el misterio y la falta de legalidad del lugar donde debe reinar un sistema por el cual hemos hecho sacrificios de todo género".63

El Argos separado definitivamente del gobierno provincial lo acusó de entorpecer su trabajo. Pero esto no era más que un síntoma de las nuevas circunstancias que se estaban viviendo: la necesidad del Argos, de la facción rivadaviana, de encarnar una tarea de mayor amplitud, de carácter nacional. Si el Argos perdió su 'ministerialismo' fue solamente en parte, porque su tarea era ahora ofrecerle al público una explicación de las decisiones tomadas en el seno del Congreso Constituyente. En estas circunstancias, el papel chocó con una serie de escollos que complicaron su publicación y circulación en la plaza porteña:

[El Argos] debe notarse mas defectuoso en la redacción, en la corrección, y tambien en la hora de reparto. Pero esto mismo nos impone respecto en ninguna manera penden de los editores del Argos, sino que son la consecuencia inmediata de una sistema adoptado exprofeso para entorpecer la emisión, y conducirle gradualmente al cese. ${ }^{64}$

Estos entre dichos suceden los primeros días de noviembre y el 3 de diciembre el Argos publicó su último número:

POR FIN EL Argos ha cesado de imprimirse en la Imprenta del Estado [antigua Imprenta Expósito] por resolución terminante del gefe de ella, y no por la voluntad de los editores, que estaba decidida á permanecer en una imprenta de que se han servido algunos años. Esto ha sido capaz por si solo de interrumpir la emisión de un papel que no puede darse en una imprenta comun, y mucho mas cuando todas las imprentas en Buenos Aires están sobrecargadas de trabajo; pero esforzará por lograr que se hagan algunos sacrificios en favor de su continuación (...). ${ }^{65}$

Entonces, el cierre del Argos se vinculó con la coyuntura porteña y nacional de fines de 1825: la actuación del Congreso Constituyente, la casi declaración de guerra con Brasil y la urgencia, para un sector de elite, de organizar políticamente a la nación. El Argos de Buenos Aires fue un periódico fundado con la intención de llevar las luces a la sociedad porteña en el proceso de modernización provincial, pero, sin embargo, fue siempre el periódico de una facción específica de la elite porteña, los rivadavianos. Cuando finalizó la publicación, los sectores dirigentes del nuevo proyecto nacional no consideraron necesario continuar con este periódico, más allá de la intención manifiesta de su editor, podemos suponer que la empresa periodística rivadaviana apuntaba en otra dirección, la nacional.

Este final del Argos nos permite realizar una nueva reflexión las sobre características de la prensa periódica de la época ¿Puede, a principios del siglo XIX, un periódico sobrevivir sin el apoyo financiero y político un gobierno? La respuesta es claramente negativa. Los periódicos del Río de la Plata, en su mayoría, cumplieron un rol político - vinculados a una facción particular - al divulgar noticias, información, ideas, etc. Esta podía responder o no a una institución gubernamental. Si podemos sostener que de esto último dependía su duración temporal. Si no se contaba con este tipo de apoyos la permanencia de un papel público era un limitada, porque 
ni los anuncios, ni el precio de venta a los suscriptores podían solventar la empresa periodística. La mayoria de los periódicos que circularon en la primera mitad de la década de 1820 no sobrepasaron el año de duración y su publicación se cargaba sobre los bolsillos de sus editores. El Argos del 23 de enero de 1822 publica en un aviso: "El editor del Patriota se forma un grato deber en avisar al público, que no ha podido realizar la redacción del $2^{\circ}$ trimestre, por no haber recogido subscripcion suficiente, y además habérsele alzado en la imprenta el precio".66 El costo material y humano que requería la tarea periodística puede ser una posible respuesta para entender porque se reitera la queja de falta de publicaciones circulando por la ciudad, muy pocos de periódicos que circularon superaron el año de vida, sólo los que tenían tras sus espaldas plumas infatigables, como la del Padre Castañeda, o recursos gubernamentales, como el Argos.

Entonces, podemos concluir que el Argos de Buenos Aires fue un periódico informativo y político que se estableció durante la primera mitad de la década de 1820 con el fin de impulsar desde la prensa periódica la gestión de gobierno realizada durante el mandato de Martin Rodríguez, enfocándose principalmente en las reformas impulsadas por el ministro de gobierno Bernardino Rivadavia. Asimismo, no fue casual que la culminación del Argos se vincule con conflictos políticos-institucionales, cuando los proyectos del grupo rivadaviano ya no se vinculaban con la institucionalización de la provincia de Buenos Aires sino que su proyección nacional a través de Congreso Constituyente. En fin, en sus casi cinco años de publicación, el Argos se tornó mucho más noticioso que ilustrado, pero siempre fue el instrumento propagandístico de una facción de la elite porteña que legitimar sus decisiones ante el pueblo el soberano. 